\title{
BMJ Open Association of genetic polymorphisms of CYP2E1, NAT2, GST and SLCO1B1 with the risk of anti-tuberculosis drug- induced liver injury: a systematic review and meta-analysis
}

Seungwon Yang, ${ }^{1}$ Se Jung Hwang, ${ }^{2}$ Jung Yun Park, ${ }^{3}$ Eun Kyoung Chung, ${ }^{2,4}$ Jangik I Lee Le $^{3,5}$

To cite: Yang S, Hwang SJ, Park JY, et al. Association of genetic polymorphisms of CYP2E1, NAT2, GST and SLC01B1 with the risk of antituberculosis drug-induced liver injury: a systematic review and meta-analysis. BMJ Open 2019;9:e27940. doi:10.1136/ bmjopen-2018-027940

- Prepublication history and additional material for this paper are available online. To view these files, please visit the journal online (http://dx.doi. org/10.1136/bmjopen-2018027940).

EKC and JIL contributed equally.

Received 19 November 2018 Accepted 11 June 2019

Check for updates

(C) Author(s) (or their employer(s)) 2019. Re-use permitted under CC BY-NC. No commercial re-use. See rights and permissions. Published by BMJ.

For numbered affiliations see end of article.

Correspondence to Dr Eun Kyoung Chung; cekchung@khu.ac.kr and Professor Jangik I Lee; jangik.lee@snu.ac.kr

\section{ABSTRACT}

Objectives The objective of this study was to investigate the association between genetic polymorphisms of $\mathrm{N}$-acetyltransferase 2 (NAT2), cytochrome P450 2E1 (CYP2E1), glutathione S-transferase (GST) and solute carrier organic anion transporter family member 1B1 (SLC01B1) and the risk of anti-tuberculosis drug-induced liver injury (ATDILI).

Design Systematic review and meta-analysis.

Data sources PubMed, Embase, Web of Science and Cochrane Reviews databases were searched through April 2019.

Eligibility criteria We included case-control or cohort studies investigating an association between NAT2, CYP2E1, GST or SLC01B1 polymorphisms and the ATDILI risk in patients with tuberculosis.

Data extraction and synthesis Three authors screened articles, extracted data and assessed study quality. The strength of association was evaluated for each gene using the pooled OR with a $95 \% \mathrm{Cl}$ based on the fixed-effects or random-effects model. Sensitivity analysis was performed to confirm the reliability and robustness of the results. Results Fifty-four studies were included in this analysis ( $\mathrm{n}=26$ for CYP2E1, $\mathrm{n}=35$ for NAT2, $\mathrm{n}=19$ for GST, $\mathrm{n}=4$ for SLC01B1). The risk of ATDILI was significantly increased with the following genotypes: CYP2E1 Rsal/Pst c1/c1 (OR $=1.39,95 \% \mathrm{Cl} 1.06$ to 1.83$)$, NAT2 slow acetylator $(\mathrm{OR}=3.30,95 \% \mathrm{Cl} 2.65$ to 4.11$)$ and GSTM1 null (OR=1.30 $95 \% \mathrm{Cl} 1.12$ to 1.52$)$. No significant association with ATDIL was found for the genetic polymorphisms of CYP2E1 Dral, GSTT1, GSTM1/GSTT1, SLC01B1 388A $>\mathrm{G}$ and SLC01B1 $521 \mathrm{~T}>\mathrm{C}(\mathrm{p}>0.05)$.

Conclusions ATDILI is more likely to occur in patients with NAT2 slow acetylator genotype, CYP2E1 Rsal/Pst/ c1/ c1 genotype and GSTM1 null genotype. Close monitoring may be warranted for patients with these genotypes.

\section{INTRODUCTION}

Tuberculosis is a rampant infectious disease caused by Mycobacterium tuberculosis. It poses a major public health threat globally with approximately 1.3 million deaths and
Strengths and limitations of this study

- This is the first meta-analysis to evaluate the association between the risk of anti-tuberculosis drug-induced liver injury (ATDILI) and solute carrier organic anion transporter family member 1B1 (SLC01B1) in patients with tuberculosis.

- We included most updated studies with the large sample sizes to better clarify the association of genetic polymorphisms with the risk of ATDILI.

- The effect of anti-tuberculosis drug dosages on the risk of ATDILI could not be accounted for in this study due to the lack of drug dosing information in the majority of the included studies.

10 million new cases in $2017 .^{1}$ The mainstay of first-line tuberculosis treatment is a four-drug combination regimen of isoniazid (INH), rifampicin (RIF), pyrazinamide (PZA) and ethambutol (EMB) during the first 2 months, followed by INH and RIF for additional 4 months. $^{2} 3$ The currently recommended therapy for tuberculosis is highly effective, resulting in high cure rates if patients are adherent to therapy. ${ }^{4}$ However, treatment adherence is often suboptimal in patients receiving the combination anti-tuberculosis therapy due to many adverse drug reactions, some of which are considered detrimental. ${ }^{5}$ One of the common adverse drug reactions associated with anti-tuberculosis medications is anti-tuberculosis drug-induced liver injury (ATDILI) affecting $2 \%$ to $28 \%$ of patients with tuberculosis. ${ }^{6}$ ATDILI could be potentially serious and fatal, resulting in the treatment interruption and ultimately, treatment failure. $^{78}$

Recently, increasing evidence suggests an association between the risk of ATDILI and genetic polymorphisms of drug-metabolising 
enzymes (DMEs) and drug transporters. ${ }^{9}$ 10 Altered enzyme activity due to polymorphic genotypes of various DMEs including cytochrome P450 2E1 (CYP2E1), N-acetyltransferase 2 (NAT2) and glutathione S-transferase (GST) can result in the accumulation of toxic substances in the liver, leading to the development of ATDILI. ${ }^{11}$ However, conflicting results have been reported regarding the association between the risk of ATDILI and genetic polymorphisms of various DMEs in patients with tuberculosis. ${ }^{91213}$ In addition to DMEs, drug transporters have been emerging as a key determinant of the pharmacokinetics and pharmacodynamics of a drug. ${ }^{14}$ Among various drug transporters, organic anion transporting polypeptide 1B1 (OATP1B1), encoded by SLCO1B1, is the major influx transporter responsible for hepatic uptake of RIF. ${ }^{15}$ Although several studies have previously examined the association between SLCO1B1 polymorphisms and the risk of ATDILI, conflicting results have been reported regarding the effect of SLCO1B1 polymorphisms on ATDILI risk. Therefore, an updated meta-analysis has been warranted to confirm the association between the ATDILI risk and genetic polymorphisms of DMEs. In our preliminary literature search, several polymorphic genes, including many DMEs, transporters and other genes such as those involved in the immune system, were identified to have an association with the risk of ATDILI. Among these, sufficient, published information was available to confirm the effect of CYP2E1, NAT2, GST, and SLCO1B1 genetic polymorphisms on the ATDILI risk through meta-analysis.

\section{Objectives}

The objective of this meta-analysis was to evaluate the association between the risk of ATDILI and genetic polymorphisms of CYP2E1, NAT2, GST and SLCO1B1 in patients with tuberculosis.

\section{METHODS}

This study was in compliance with the Meta-analysis Of Observational Studies in Epidemiology checklist for reporting the study design, search strategy, methods, results and conclusions (online supplementary table S1). Three authors (SY, JYP and SJH) independently conducted a literature search, study selection, quality assessment and data extraction. Any discrepancies were adjudicated by corresponding authors (JIL and EKC).

\section{Search strategy}

Electronic databases of PubMed, Embase, Web of Science and Cochrane Reviews were systematically searched from their inception to April 2019 to identify relevant studies evaluating the association of NAT2, CYP2E1, GST and SLCO1B1 polymorphisms with ATDILI risk. A comprehensive literature search was conducted using a combination of the following keywords and Medical Subject Heading terms: ('genetic polymorphism' or 'NAT2' or 'CYP2E1' or 'GST or 'SLCO1B1' or 'drug-metabolizing enzymes' or 'drug transporter') AND ('anti-tuberculosis agents drug-induced liver injuries' or 'hepatotoxicity'). The detailed search strategies for each electronic database used in this analysis are presented in online supplementary table S2. The reference lists in the selected reviews and meta-analyses were reviewed to ensure the inclusion of all relevant evidence in this analysis.

\section{Study selection}

Studies were considered eligible if they met all of the following inclusion criteria: (1) studies in patients with tuberculosis receiving anti-tuberculosis drug regimen; (2) studies with the control group of patients with tuberculosis, tolerant of anti-tuberculosis medications; (3) studies evaluating the association between the occurrence of ATDILI and genetic polymorphisms of CYP2E1, NAT2, GST and SLCO1B1 388A $>$ G and 521T $>\mathrm{C}$ and (4) case-control or cohort observational studies. Excluded studies were as follows: (1) studies available only in the form of abstracts or meeting posters, (2) review or meta-analysis articles, (3) studies providing insufficient data necessary for the statistical data analysis, (4) studies in non-English language, (5) non-human studies including animal and in vitro studies, (6) studies with unpublished data, (7) studies providing insufficient information on genotyping methods and (8) healthy controls.

\section{Quality assessment and data extraction}

The quality of included studies was assessed using the revised Little's recommendation based on the following criteria $^{16}{ }^{17}$ : (1) scientific design, (2) definite inclusion of study population, (3) explicit information on study population, (4) explicit diagnostic criteria of ATDILI, (5) genetic detection method, (6) appropriate statistical analysis and (7) logical discussion of study bias. Studies with an overall score of $\geq 4$ (range 0 to 7 ) were considered high quality and retained in the analysis.

The following data were extracted from each study using a standardised extraction form: (1) name of the first author, (2) year of publication, (3) the polymorphic gene(s) and genotype(s) under investigation, (4) ethnicity, (5) sample size, (6) mean or median age, (7) sex distribution, (8) anti-tuberculosis drug regimens, (9) diagnostic criteria of ATDILI, (10) genotyping methods and (11) the number of cases and controls for each polymorphic genotype.

\section{Statistical analysis}

The genotypes were analysed based on the following proposed genetic risk model: (1) NAT2 (slow acetylator vs intermediate and fast acetylator), (2) CYP2E1 (c1/ $\mathrm{c} 1$ vs $\mathrm{c} 1 / \mathrm{c} 2$ and $\mathrm{c} 2 / \mathrm{c} 2$ for the RsaI/PstI polymorphism, $\mathrm{D} / \mathrm{D}$ ws $\mathrm{D} / \mathrm{C}$ and $\mathrm{C} / \mathrm{C}$ for the DraI polymorphism), (3) GSTM1 (null vs non-null), (4) GSTT1 (null vs non-null), (5) GSTM1/GSTT1 (dual-null vs one-null or non-null) and (6) SLCO1B1 388A $>$ Gand 521T $>$ C polymorphisms. The genetic risk models for NAT2, CYP2E1, GSTM1, GSTT1 and GSTM1/GSTT1 have been studied in previous 
studies. ${ }^{9} 1819$ Based on these previous studies, the most clinically significant and plausible model for each polymorphic gene was selected. Due to the relative paucity of data suggesting the most clinically relevant genetic model for SLCO1B1 388A $>$ Gand 521T>C polymorphisms, all three genomic models including dominant, recessive and additive models were evaluated. The Mantel-Haenszel or DerSimonian-Laird method based on fixed-effects or random-effects models, respectively, were used depending on the presence of heterogeneity. ${ }^{20}{ }^{21}$ The random-effects model was used in the presence of significant heterogeneity; otherwise, the fixed-effects model was used to estimate the total effect of a polymorphic gene genotype on the risk of ATDILI. Heterogeneity of study outcomes among included studies was evaluated using Cochran's $Q$ test $(Q)$ and quantified using Higgin's $\mathrm{I}^{2}$ test. Significant heterogeneity was defined as the $\mathrm{I}^{2}$ score of $>40 \%$ accompanied by $\mathrm{p}<0.10$ from the Cochran's $Q$ test. ${ }^{22}$ The strength of the association between the genetic polymorphisms and the risk of ATDILI was estimated using pooled ORs with the corresponding 95\% CIs. The statistical significance of an OR was defined as $\mathrm{p}<0.05$ from the $\mathrm{Z}$ test.

Subgroup analysis was performed based on ethnicity, anti-tuberculosis drug regimen used and the type of study design. Sensitivity analysis was conducted to assess the robustness of the results and to identify the source of heterogeneity using the leave-one-out method. In each analysis, one study was deleted, and with the one study left out, the meta-analysis was performed; this process was repeated until every study had been deleted from our included study pool for each tested polymorphic gene. Publication bias was evaluated with a symmetrical funnel plot. Statistical analyses were performed using Review Manager Software V.5.3 (Cochrane Collaboration, London, UK).

\section{Patient and public involvement}

Patients and public were not involved in the design of this study.

\section{RESULTS}

\section{Study selection and characteristics}

Overall, 388 articles were identified through electronic database search and three articles through manual search by reviewing the reference lists of retrieved articles. After removing 99 duplicates, 289 articles were screened for relevance based on the title and abstract. Among them, 72 relevant articles were assessed for eligibility through full-text evaluations. Finally, a total of 54 articles which met the inclusion criteria were included in our analysis (figure 1). Among the 54 studies, 26 studies were included for CYP2E1, 35 studies for NAT2, 19 studies for GST (19 for GSTM1, 17 for GSTT1 and 11 for GSTM1/GSTT1) and four studies for SLCO1B1 388A $>$ G and 521T $>$ C.

Table 1 summarises the characteristics of the included studies. Across the included studies, large variability in study population was observed in terms of ethnicity (Chinese, Japanese, Korean, Indian, Taiwanese, Brazilian, Caucasian, Iranian, Tunisian and Turkish), age (mean or median age ranging from 27 to 70 years) and sex (the proportion of males ranging from $13 \%$ to $90 \%$ ). Patients in our included studies received either monotherapy with INH or RIF or a combination therapy including a four-drug regimen of INH, RIF, PZA and EMB for the treatment of tuberculosis. ATDILI was defined as an elevated serum alanine aminotransferase concentration by 1.5 -fold to 5 -fold or greater above the upper limit of normal depending on the study. The quality score of the included studies was 6 or greater based on the revised Little's recommendation (table 1, online supplementary table S3). ${ }^{16}{ }^{17}$ Genotype distribution and genotyping method used in the included studies are summarised for each polymorphic gene in online supplementary table $S 4$ to S7. Funnel plots for CYP2E1, NAT2, GST and SLCO1B1 are provided in online supplementary figure S8. None of the funnel plots showed an asymmetric inverted funnel shape, indicating the absence of potential publication bias.

\section{CYP2E1}

For the CYP2E1 RsaI/PstI polymorphism, 24 studies with 1293 cases and 5450 controls were included in our primary analysis. Using the random-effects model, the pooled estimates of all included studies $(n=24)$ showed a significant association between the risk of ATDILI and the CYP2E1 RsaI/PstI polymorphism (OR for the $\mathrm{c} 1 / \mathrm{c} 1$ genotype $=1.39,95 \%$ CI 1.06 to $1.83, \mathrm{p}=0.02 ; \mathrm{I}^{2}=60 \%, \mathrm{P}_{\text {hetero }}$ geneity $<0.0001)$ (figure $2 \mathrm{~A}$ ). In the subgroup analysis based on ethnicity and anti-tuberculosis drug regimens, the risk of ATDILI was significantly increased for the CYP2E1 $R s a \mathrm{I} /$ Pst $\mathrm{l} 1 / \mathrm{c} 1$ genotype in East Asian patients $(\mathrm{OR}=1.62$, $95 \%$ CI 1.26 to $\left.2.36, \mathrm{p}=0.01 ; \mathrm{I}^{2}=69 \%, \mathrm{P}_{\text {heterogeneity }}=0.0006\right)$ and in patients receiving a combination of anti-tuberculosis medications ( $\mathrm{OR}=1.35,95 \%$ CI 1.01 to $1.79, \mathrm{p}<0.00001$; $\mathrm{I}^{2}=61 \%, \mathrm{P}_{\text {heterogenenity }}=0.0002$ ) (online supplementary table S9). No significant association was observed between the risk of ATDILI and the CYP2E1 RsaI/PstI c1/c1 genotype when evaluating studies with the same study design only (ie, either case-control studies or cohort studies) (online supplementary table S9).

In our primary analysis for the CYP2E1 DraI polymorphism with six studies including 233 cases and 1272 controls, no significant association was observed using the fixed-effects model between the risk of ATDILI and the DraI polymorphism (OR for the $\mathrm{D} / \mathrm{D}$ genotype $=0.93$, $95 \% \mathrm{CI} 0.68$ to $\left.1.27, \mathrm{p}=0.64 ; \mathrm{I}^{2}=0 \%, \quad \mathrm{P}_{\text {hetergonenity }}=0.51\right)$ (figure 2B).

\section{NAT2}

Overall, 35 studies with 1323 cases and 7319 controls were included in our primary analysis for the NAT2 polymorphism. Using the random-effects model, the pooled estimates of all included studies $(\mathrm{n}=35)$ showed a significant association between the risk of ATDILI and the NAT2 


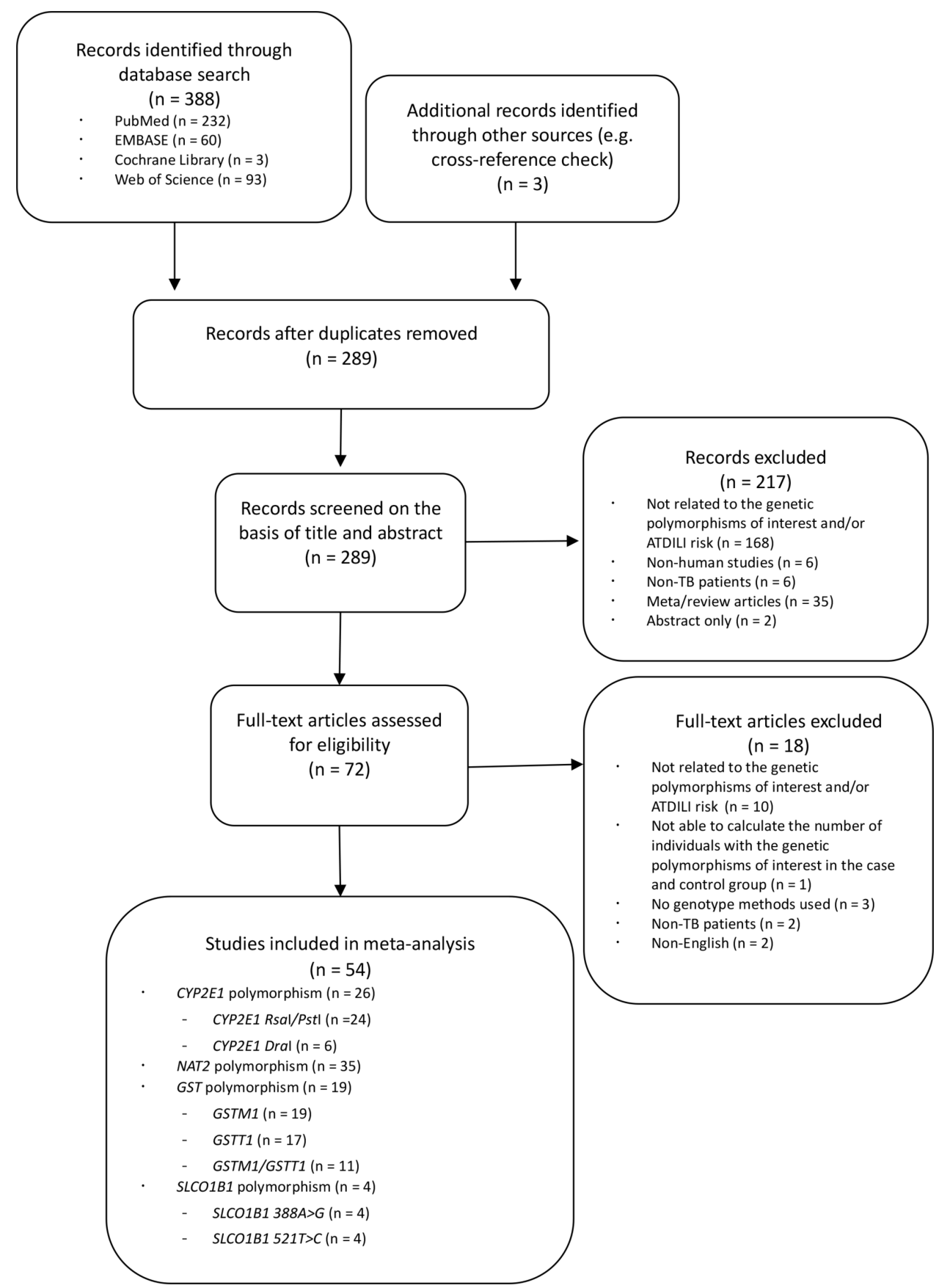

Figure 1 Study selection process flowchart. ATDILI, anti-tuberculosis drug-induced liver injury; CYP2E1, cytochrome P450 2E1; GSTM1, glutathione S-transferase Mu 1; GSTT1, glutathione S-transferase Theta 1; NAT2, N-acetyltransferase 2; SLCO1B1, solute carrier organic anion transporter family member 1B1; TB, tuberculosis.

polymorphism (OR for the slow acetylator genotype $=3.30$, $95 \%$ CI 2.65 to $\left.4.11, \mathrm{p}<0.00001 ; \mathrm{I}^{2}=54 \%, \mathrm{P}_{\text {heterogeneity }}<0.0001\right)$ (figure 3). In the subgroup analysis based on ethnicity, anti-tuberculosis drug regimens used, and study design, the risk of ATDILI was significantly increased in slow acetylators compared with fast or intermediate acetylators in all subgroups (online supplementary table S10).

\section{GST}

For the GSTM1 polymorphism, a total of 19 studies with 977 cases and 5119 controls were included in our primary analysis. Using the fixed-effects model, the pooled estimates of all included studies $(n=19)$ showed a significant association between the risk of ATDILI and the GSTM1 polymorphism (OR for the GSTM1 null genotype $=1.30,95 \%$ CI 1.12 to $1.52, \mathrm{p}=0.0007 ; \mathrm{I}^{2}=33 \%, \mathrm{P}_{\text {hetero- }}$ geneity $=0.08$ ) (figure $4 \mathrm{~A}$ ). When studies were stratified for ethnicity, the risk of ATDILI was significantly increased for the GSTM1 null genotype in Indians $(\mathrm{OR}=1.68$, $95 \%$ CI 1.30 to $2.19, \mathrm{p}<0.0001 ; \mathrm{I}^{2}=36 \%, \mathrm{P}_{\text {heterogeneity }}=0.15$ ) (online supplementary table S11). In the subgroup analyses by study design, the estimated OR (95\% CI, p value; $\left.\mathrm{I}^{2}, \mathrm{P}_{\text {heterogeneity }}\right)$ for the GSTM1 null genotype relative to the 
嗂产

ठै

言

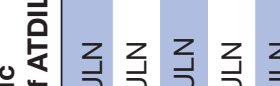

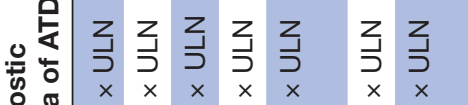

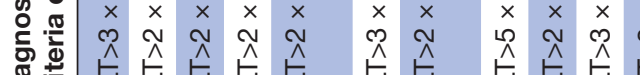

z z z z z z z z

z

z) z z z

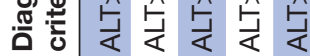

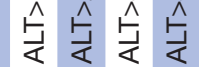

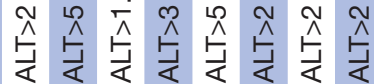

$m \sim N$ i $N$ m N

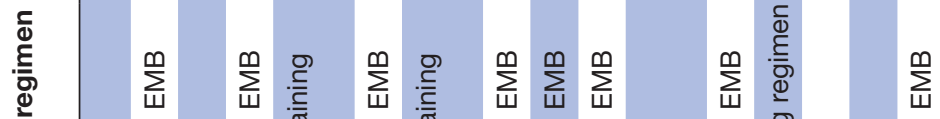

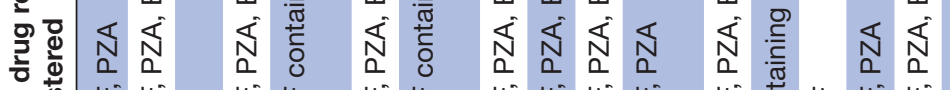

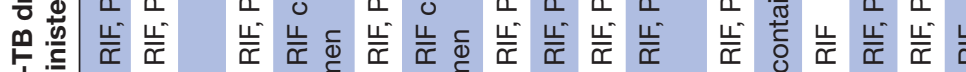

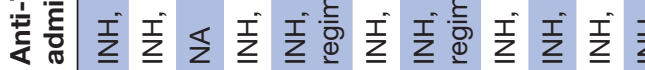

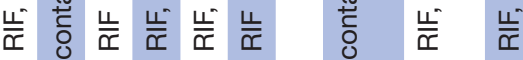

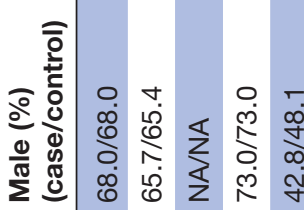

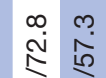

官

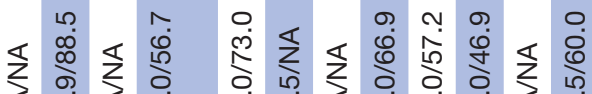

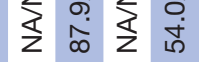

变

๓

कृ

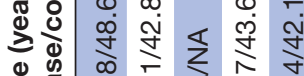

एक

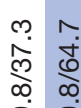

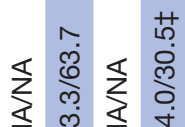

蒙

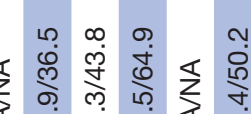

iे

之

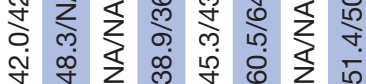

क्ष

至 高递贫

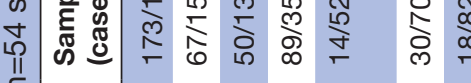

价 $\bar{\sigma}$

今े

ल)

8

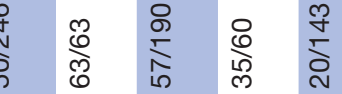

\section{$\frac{\sqrt{2}}{\frac{2}{5}}$}

है

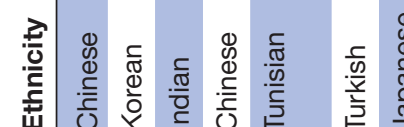

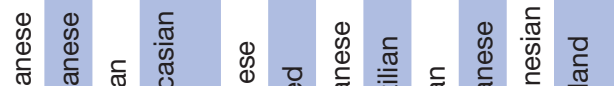

恼

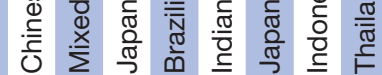

ঙ্ল

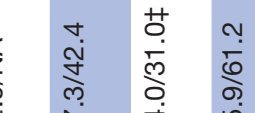

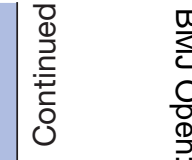

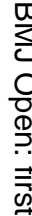

章

क

$\vec{\circ}$

$\overrightarrow{\vec{\omega}}$

$\frac{1}{3}$

옹

인

Ðै

은

站

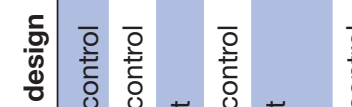

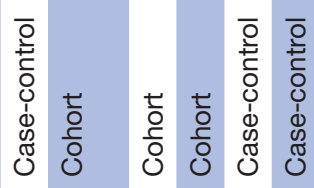

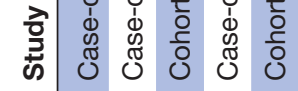

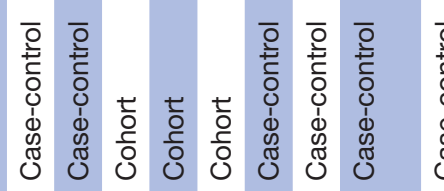

을

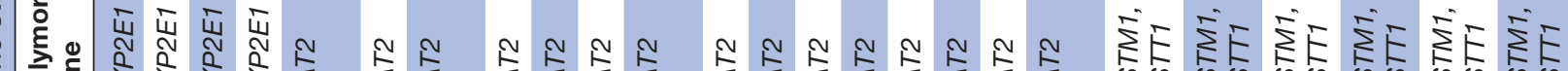

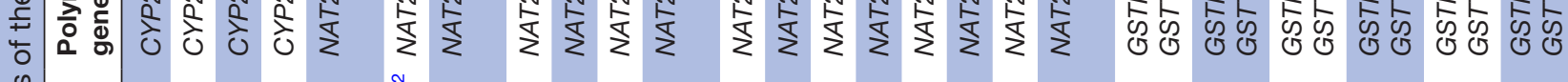

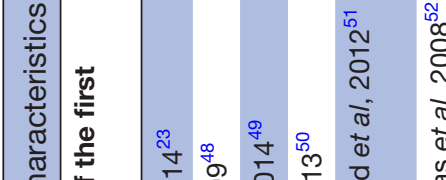

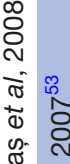

U

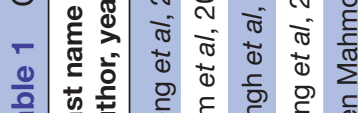

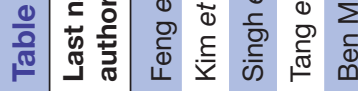

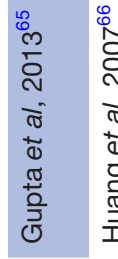

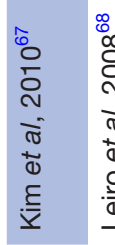

$\frac{\sqrt[7]{\frac{0}{\pi}}}{\stackrel{\pi}{\pi}}$ 


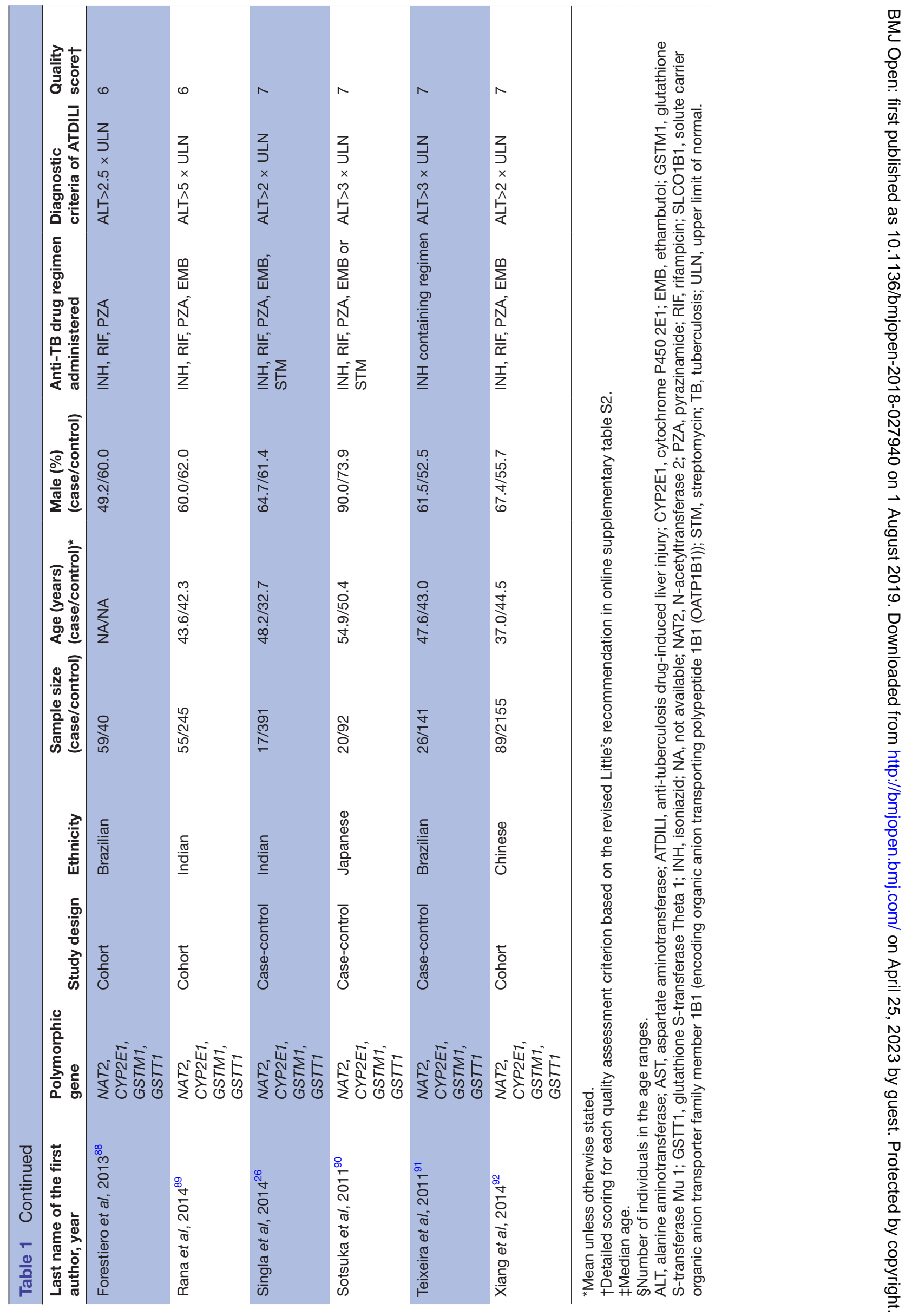


(A) CYP2E1 RsaI/PstI c1/c1 genotype compared to $c 1 / c 2+c 2 / c 2$ genotypes

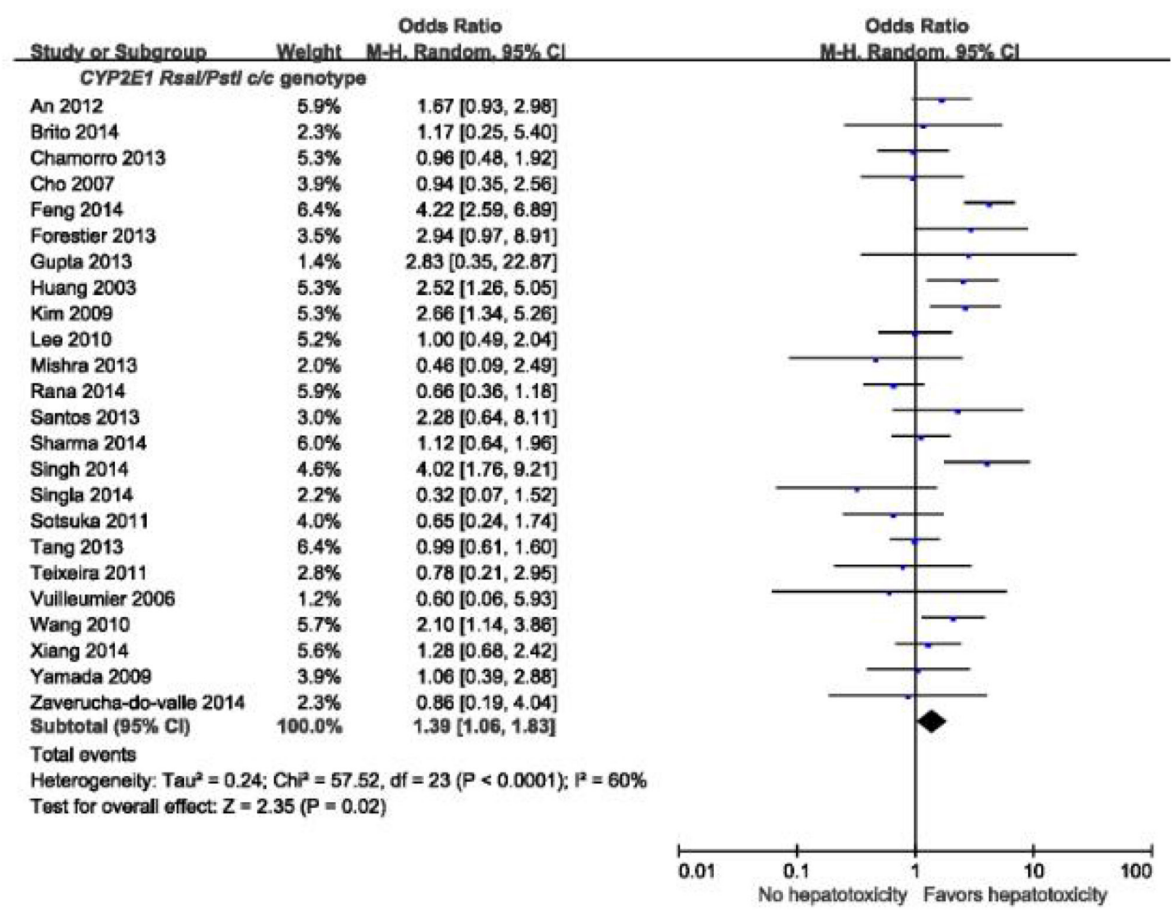

(B) CYP2E1 DraI D/D genotype compared to D/C $+C / C$ genotypes.

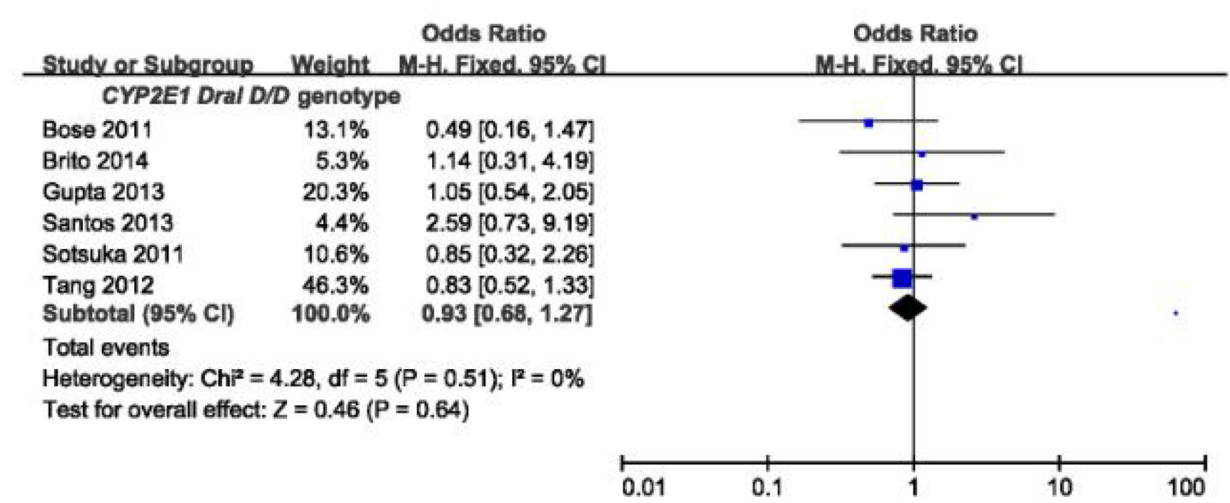

Figure 2 Risk of anti-tuberculosis drug-induced liver injury in patients with the CYP2E1 (A) Rsal/Pstl c1/c1 genotype compared with c1/c2+c2/c2 genotypes and (B) Dral D/D genotype compared with D/C+C/C genotypes. CYP2E1, cytochrome P450 $2 \mathrm{E} 1$.

non-null genotype was 1.41 (1.04 to $1.93, \mathrm{p}=0.03 ; \mathrm{I}^{2}=44 \%$, $\mathrm{P}_{\text {heterogeneity }}=0.08$ ) in cohort studies and 1.25 (1.01 to 1.55 , $\left.\mathrm{p}=0.20 ; \mathrm{I}^{2}=29 \%, \mathrm{P}_{\text {heterogeneity }}=0.17\right)$ in case-control studies, respectively (online supplementary table S11).

For the GSTT1 and GSTM1/GSTT1 polymorphisms, 17 studies ( 768 cases, 4823 controls) and 11 studies (547 cases, 4233 controls) were included in our primary analyses, respectively. The risk of ATDILI was not significantly associated with the GSTT1 polymorphism (OR for the null genotype $=1.03,95 \%$ CI 0.85 to $1.25, \mathrm{p}=0.76 ; \mathrm{I}^{2}=16 \%$, $\left.\mathrm{P}_{\text {heterogeneity }}=0.26\right)$ or the GSTM1/GSTT1 polymorphism (OR for the dual-null genotype $=1.05,95 \%$ CI 0.67 to 1.62 , $\mathrm{p}=0.84 ; \mathrm{I}^{2}=59 \%, \mathrm{P}_{\text {hetergeneity }}=0.006$ ) (figure $4 \mathrm{~B}$ and $\mathrm{C}$ ). When studies were stratified for ethnicity, anti-tuberculosis drug regimens used, and study design, no subgroups showed significant association between the risk of ATDILI and the GSTT1 and the GSTM1/GSTT1 polymorphisms (online supplementary table $\mathrm{S} 11$ ).

\section{SLC01B1}

For the SLCO1B1 388A $>$ G polymorphism, four studies with 302 cases and 913 controls were included in our primary analysis. Using the dominant, recessive or additive genomic model, no significant association was observed between the risk of ATDILI and the SLCO1B1 $388 \mathrm{~A}>$ G polymorphism (table 2). For the SLCO1B1 $521 \mathrm{~T}>\mathrm{C}$ polymorphism, four studies with 314 cases and 912 controls were included in our primary analysis. No 


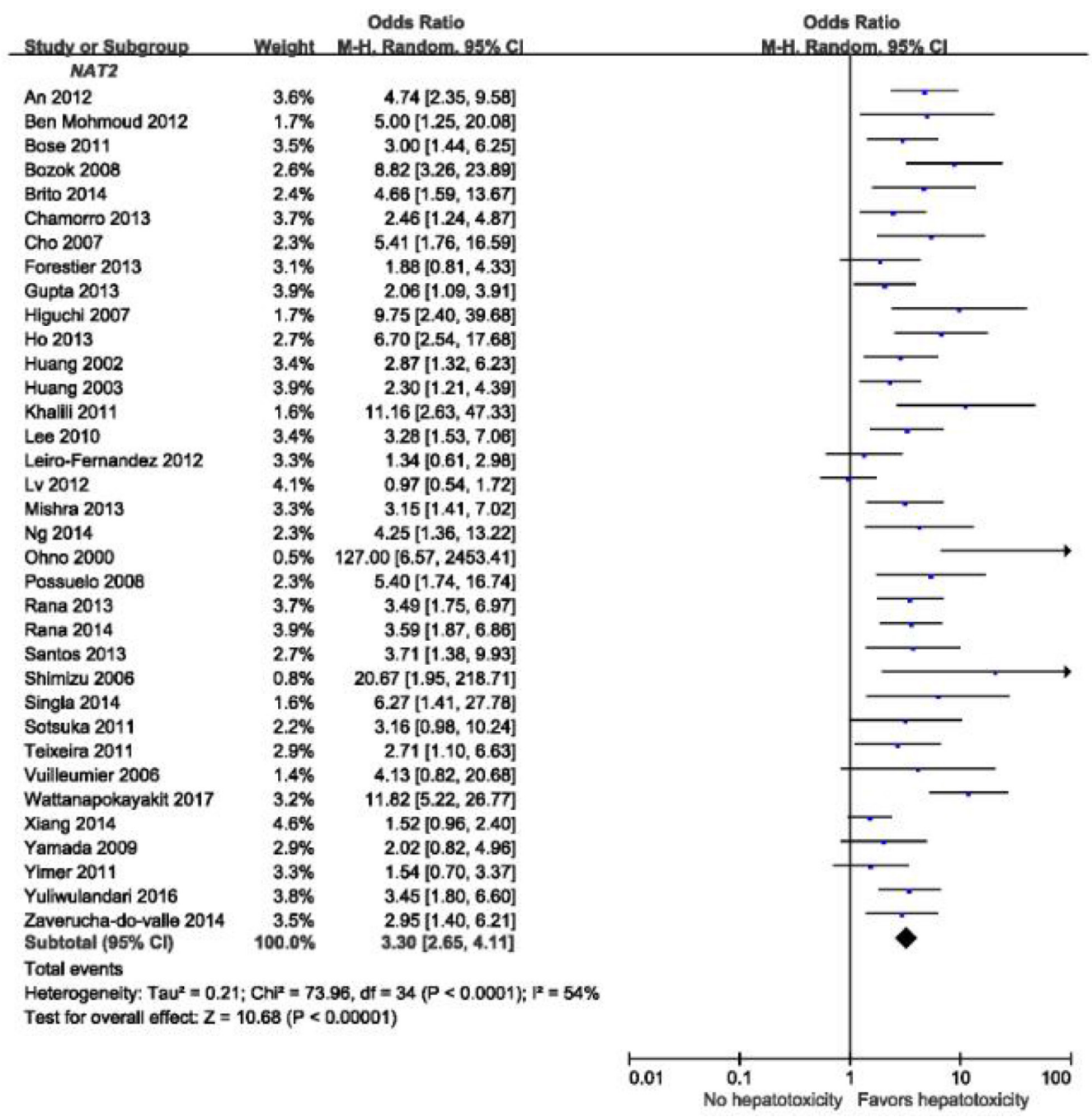

Figure 3 Risk of anti-tuberculosis drug-induced liver injury in patients with the NAT2 slow acetylator genotype compared with those with the intermediate/fast acetylator genotypes. NAT2, N-acetyltransferase 2.

significant association was found between the ATDILI risk and the SLCO1B1 521T>C polymorphism under the dominant, recessive or additive genetic model (table 2). Due to the lack of significant association between the risk of ATDILI and the tested SLCO1B1 genetic polymorphisms in our primary meta-analysis, subgroup analyses were not performed for these genetic polymorphisms.

\section{Sensitivity analysis}

Our primary analysis results showed significantly high heterogeneity between studies for CYP2E1 RsaI/Pst $\left(\mathrm{I}^{2}=60 \%, \quad \mathrm{p}<0.0001\right), \quad$ NAT2 $\quad\left(\mathrm{I}^{2}=54 \%, \quad \mathrm{p}<0.0001\right)$, GSTM1/GSTT1 $\left(\mathrm{I}^{2}=59 \%, \mathrm{p}=0.006\right)$ and SLCO1B1 $521 \mathrm{~T}>\mathrm{C}$ (dominant genetic model: $\mathrm{I}^{2}=66 \%, \mathrm{p}=0.03$ ) polymorphisms. This high heterogeneity between studies may be due to substantial differences in ethnicity, anti-tuberculosis drug regimen, the genotyping method used, study design and diagnostic criteria of ATDILI among the included studies (table 1). Through the sensitivity analyses, outlier studies were identified as the major source of heterogeneity. After removing these outlier studies, heterogeneity was substantially reduced $\left(\mathrm{I}^{2}=60 \%\right.$ to $42 \%$ for CYP2E1 RsaI/PstI ${ }^{23} \mathrm{I}^{2}=54 \%$ to $34 \%$ for $N A T 2^{24} 25$, $I^{2}=59 \%$ to $0 \%$ for GSTM1/GSTT ${ }^{2627}$ and $I^{2}=66 \%$ to $0 \%$ for SLCO1B1 521T>C dominant genetic $\operatorname{model}^{28}$ ). The overall results for the association between the risk of ATDILI and these genetic polymorphisms after excluding the outlier studies stayed the same as those from our primary analysis results.

\section{DISCUSSION}

In this study, we conducted a large-scale meta-analysis evaluating the association between the risk of ATDILI and genetic polymorphisms of $S L C O 1 B 1$ as well as various DMEs including CYP2E1, NAT2 and GST to provide more updated, comprehensive and compelling evidence. Compared with previous meta-analyses, our present study included a larger number of studies, which may sufficiently increase the statistical power compared with individual studies. However, a limited number of studies for the SLCO1B1 genetic polymorphisms were included $(n=4)$. Consistently with previous studies, our current study suggested a significantly increased risk of ATDILI 
(A) GSTM1 null genotype compared to the non-null genotype

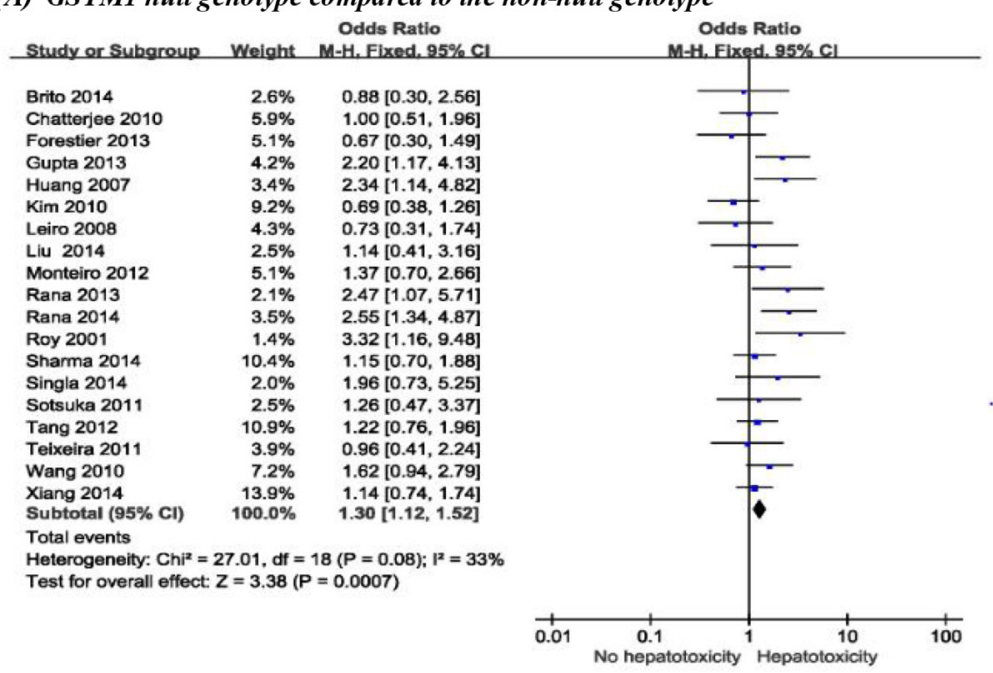

(B) GSTT1 null genotype compared to the non-null genotype

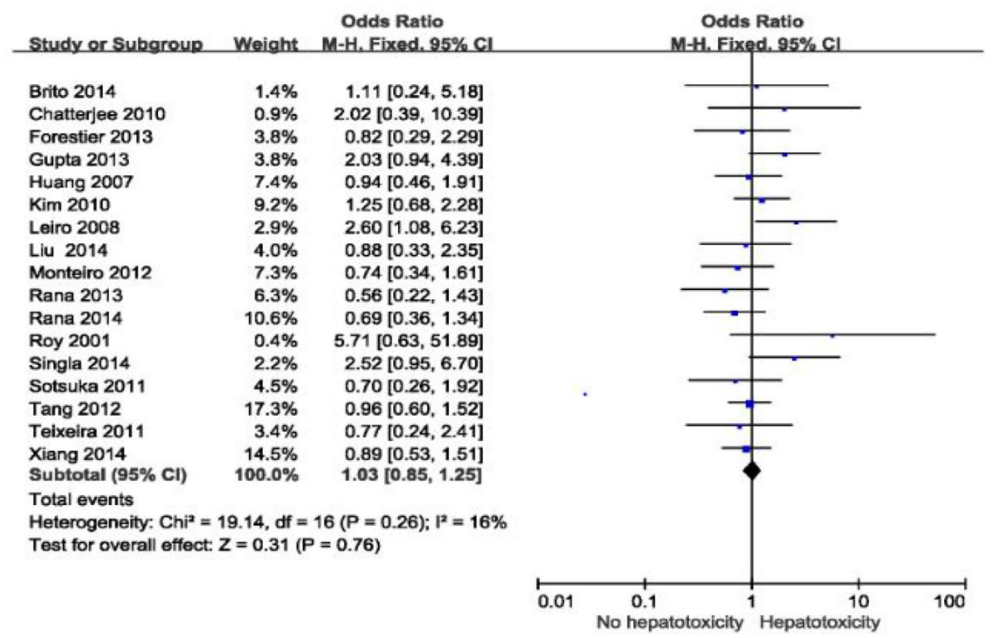

(C) GSTM1/GSTT1 dual-null genotype compared to the one- and non-null genotypes

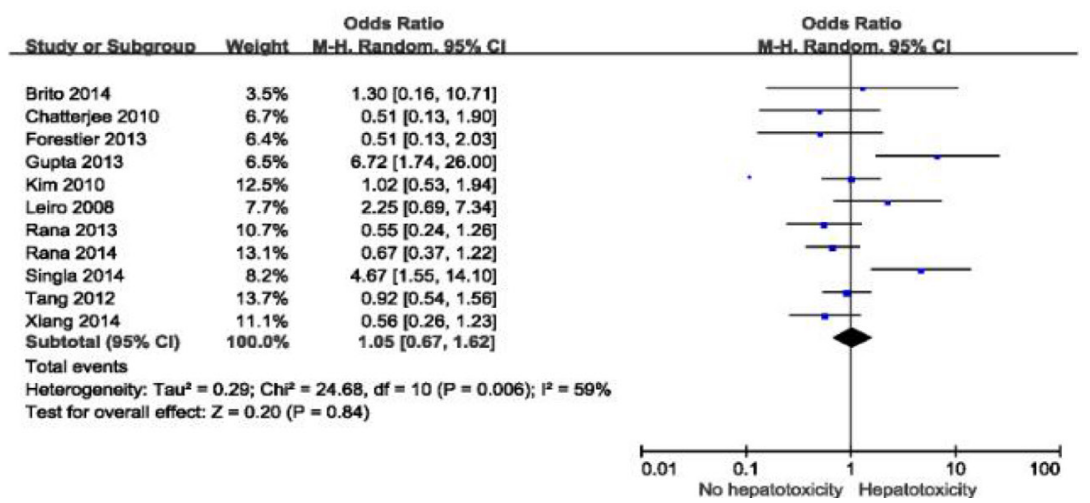

Figure 4 Risk of anti-tuberculosis drug-induced liver injury in patients with (A) the GSTM1 null genotype compared with the non-null genotype, (B) the GSTT1 null genotype compared with the non-null genotype and (C) the GSTM1/GSTT1 dual-null genotype compared with the one-null and non-null genotypes. GSTM1, glutathione S-transferase Mu 1; GSTT1, glutathione S-transferase Theta 1.

in patients with the CYP2E1 RsaI/PstI c1/c1 genotype (OR=1.39, 95\% CI 1.06 to 1.83$)$, the NAT2 slow acetylator genotype $(\mathrm{OR}=3.30,95 \% \mathrm{CI} 2.65$ to 4.11$)$ and the GSTM1 null genotype $(\mathrm{OR}=1.30,95 \% \mathrm{CI} 1.12$ to 1.52$){ }^{9} 1229$ Among these genotypes, the largest increase in the risk of ATDILI was shown in patients with the NAT2 slow acetylator genotype. In contrast, no significant association was observed between the risk of ATDILI and the genetic polymorphisms of CYP2E1 DraI, GSTT1, GSTM1/GSTT1, $S L C O 1 B 1388 A>G$ and $S L C O 1 B 1521 T>C$. Caution needs to be exercised when interpreting this study finding because the lack of significant association between these 
Table 2 Association between the SLCO1B1 polymorphisms and the risk of anti-tuberculosis drug-induced liver injury

\begin{tabular}{|c|c|c|c|c|c|c|c|c|}
\hline Polymorphism & Genetic model & & $\begin{array}{l}\text { Number of } \\
\text { studies }\end{array}$ & OR $(95 \% \mathrm{Cl})$ & $P$ value & $\mathrm{I}^{2}, \%$ & $\mathbf{P}_{\text {heterogeneity }}$ & $\begin{array}{l}\text { Model } \\
\text { of meta- } \\
\text { analysis }\end{array}$ \\
\hline \multirow{2}{*}{$\begin{array}{l}\text { SLCO1B1 } \\
388 A>G \\
(r s 2306283)\end{array}$} & Dominant model & $A A+A G$ vs $G G$ & 4 & 1.00 (0.76 to 1.31$)$ & 1.00 & 0 & 0.73 & Fixed \\
\hline & Additive model & $A A$ vs $G G$ & 4 & 1.36 (0.85 to 2.15$)$ & 0.20 & 0 & 0.98 & Fixed \\
\hline \multirow{2}{*}{$\begin{array}{l}\text { SLCO1B1 } \\
521 T>C \\
\text { (rs4149056) }\end{array}$} & Dominant model & $\mathrm{CC}+\mathrm{TC}$ vs TT & 4 & 0.74 (0.43 to 1.28$)$ & 0.28 & 66 & 0.03 & Random \\
\hline & Additive model & CC vs TT & 4 & 1.27 (0.42 to 3.84$)$ & 0.67 & 0 & 0.61 & Fixed \\
\hline
\end{tabular}

SLC01B1, solute carrier organic anion transporter family member $1 \mathrm{~B} 1$.

polymorphisms and the risk of ATDILI might be due to small sample sizes and the low frequency of ATDILI reported in patients with these genetic polymorphisms.

When evaluating the impact of the CYP2E1 RsaI/PstI and DraI genetic polymorphisms on the risk of ATDILI in our study, patients with the $R s a \mathrm{I} / P s t \mathrm{I} \mathrm{c} 1 / \mathrm{c} 1$ genotype were 1.39-times more likely to develop ATDILI. Similarly, in a previous meta-analysis by Deng and colleagues, the risk of ATDILI was 1.4-times higher in patients with the RsaI/PstI c1/c1 genotype compared with other genotypes. ${ }^{30}$ In the liver, INH is metabolised by NAT2 to acetylisoniazid which is consequently oxidised by CYP2E1 to reactive hepatotoxic intermediates. ${ }^{31} 32$ The increased inducibility or greater activity of CYP2E1 in patients with the CYP2E1 $R s a \mathrm{I} / P s t \mathrm{I} \mathrm{c1/c1}$ genotype may result in the production of more intermediate hepatotoxins, ultimately leading to the increased risk of ATDILI. ${ }^{31} 32$ Our subgroup analysis showed a significantly increased risk of ATDILI in the CYP2E1 RsaI/PstI c1/c1 genotype carriers of East Asian ethnicity (S9 Table), suggesting a potential gene-ethnicity interaction. ${ }^{33}$ A previous study identified age, female sex, white race, non-Hispanic ethnicity, lower body mass index, elevated plasma aspartate transaminase concentrations at baseline and 9 months of daily INH use as risk factors for ATDILI. ${ }^{34}$ Considering their race, ethnicity and relatively lower body mass index compared with other ethnicities, East Asians may be at an increased risk of ATDILI. As the CYP2E1 RsaI/PstI c1 allele frequency is relatively low in this population ( $79.8 \%$ vs $88.5 \%$ to $99.8 \%$ in other ethnicities), the ethnicity itself might play an important role in developing hepatotoxicity through gene-ethnicity interaction. ${ }^{35}$ Furthermore, the relatively high frequency of c2 allele in this population might serve as a good control to estimate the effect of $\mathrm{c} 1$ allele on the risk of ATDILI; the rarity of this minor allele in other ethnicities could make it difficult to evaluate the association between the ATDILI risk and this genetic polymorphism. ${ }^{35}$ In addition to ethnicity, combination anti-tuberculosis therapy was shown to significantly increase the risk of ATDILI in patients with the CYP2E1 RsaI/PstI c1/c1 genotype (S9 Table). This is consistent with previous study findings because hepatotoxicity commonly occurs with anti-tuberculosis drugs such as INH and RIF and thus, use of more than one hepatotoxic anti-tuberculosis medication increases the risk of ATDILI. ${ }^{7}$

Similar to previous studies, our current study suggested a significantly increased risk of ATDILI in patients with the NAT2 slow acetylator genotype compared with those with intermediate/fast acetylator genotypes. ${ }^{9}{ }^{29}$ The risk of ATDILI in slow acetylators remained significantly increased in all tested subgroups regardless of ethnicity and the anti-tuberculosis drug regimen used (S10 Table). The frequencies of NAT2 slow acetylator alleles are highly variable between ethnic groups, ranging from 32\% in Koreans to $76 \%$ in Caucasians. ${ }^{36}$ Despite this large inter-ethnic variability in the NAT2 polymorphic allele frequency, the $N A T 2$ slow acetylator genotype consistently and significantly increased the risk of ATDILI across all ethnicities, suggesting the critical role of NAT2 polymorphism in the development of ATDILI. In addition, the increased risk of ATDILI in slow acetylators receiving INH monotherapy or combination therapy further highlights the importance of the NAT2 polymorphism in the development of INH-induced hepatotoxicity. The clearance of INH is slower in slow acetylators compared with rapid or intermediate acetylators, resulting in the accumulation of INH in these patients. ${ }^{37} 38$ This high level of INH may increase the risk of ATDILI in patients with tuberculosis carrying NAT2 slow acetylator genotype due to immune-mediated liver injury through the binding of INH to liver proteins. ${ }^{39}$ Therefore, clinicians should closely monitor patients with tuberculosis carrying the NAT2 slow acetylator genotype for hepatotoxicity when INH-based treatment is administered to these patients.

According to previous studies, GST enzymes, particularly those coded by GSTM1 and GSTT1 loci, are associated with the risk of drug-induced hepatotoxicity. ${ }^{9}{ }^{40}$ Similar to previous studies, our current study demonstrated a significantly increased risk of ATDILI in individuals with the GSTM1 null genotype compared with those with the non-null genotype; however, the risk of ATDILI was not affected by the GSTT1 or GSTM1/GSTT1 genetic polymorphisms. GSTs are important enzymes to detoxify various xenobiotics and play an essential role in INH metabolism by eliminating acetyldiazene ketene acetylonium ion, which is a possibly hepatotoxic 
free radical metabolite of INH, from the body through GSTM1. This may account for the significant association of the ATDILI risk with the GSTM1 genotype, but not with the GSTT1 or GSTM1/GSTT1 genotypes. ${ }^{90}$ Our subgroup analysis showed a significantly increased risk of ATDILI in the GSTM1 null genotype carriers of Indian ethnicity; although not statistically significant, the risk of ATDILI was relatively high in the East Asian population with the GSTM1 null genotype (online supplementary table S11). Considering the substantial difference in the GSTM1 null allele frequency between Indians (29.6\%) and East Asians (52.1\%), a potential gene-ethnicity interaction may exist based on their race, ethnicity and body size as aforementioned. ${ }^{341}$ Other characteristics than the GSTM1 polymorphism in these ethnicities may play a more important role in the development of ATDILI. In addition, when studies were stratified by study design, the risk of ATDILI was significantly increased in patients with the GSTM1 null genotype for cohort studies only, but not for case-control studies, probably due to a relatively larger sample size with cohort studies compared with case-control studies.

SLCO1B1 encodes OATP1B1 which is a major influx drug transporter responsible for the hepatic uptake of various endogenous and exogenous substances including RIF. ${ }^{42}$ Previous studies showed significantly altered systemic exposure of RIF in carriers of the SLCO1B1 polymorphism. ${ }^{43}{ }^{44}$ To our knowledge, only four studies have been conducted to examine the association between the ATDILI risk and the SLCO1B1 genetic polymorphisms. ${ }^{10284245}$ Various single nucleotide polymorphisms of SLCO1B1 were evaluated in these studies; however, SLCO1B1 388A $>\mathrm{G} \quad(\mathrm{rs} 2306283)$ and $521 \mathrm{~T}>\mathrm{C}$ (rs4149056) were the only polymorphisms assessed in common. ${ }^{10284245}$ Therefore, to maximise the sample size in our current meta-analysis, we examined the association between the risk of ATDILI and the polymorphic genotypes of SLCO1B1 388A $>$ Gand 521T>C. Similar to each of the included studies, we did not find significant difference in the risk of ATDILI among patients with different SLCO1B1 388A $>$ G and 521T $>$ C genotypes.

There are limitations to this study. First, due to the lack of information regarding other patient characteristics potentially associated with ATDILI, our estimated ORs were not adjusted based on the potential risk factors such as age, anti-tuberculosis drug dosages, alcohol consumption, cigarette smoking and other lifestyle characteristics. $^{76}$ Second, our literature search limited to the articles published in English may lead to language bias. Third, a specific causative agent of ATDILI could not be identified in our analysis because most patients in our included studies received a combination regimen of anti-tuberculosis drugs. Fourth, only the limited number of polymorphic genotypes were assessed for the association with the risk of ATDILI, particularly for SLCO1B1. In addition, only one genetic model was used for CYP2E1, NAT2 and GST when evaluating the association between genetic polymorphisms of these genes and the risk of
ATDILI. Although we acknowledge dominant, recessive and additive genomic models can be used for two alleles, it could not be applied to our meta-analysis because we compared patients with different genotype-based phenotype, that is, slow acetylator versus fast/intermediate acetylator and null vs. non-null GSTs. Multiple allelic variants or allele subgroups may represent the same phenotype (eg, $N A T 2 * 5 \mathrm{~B}, * 6 \mathrm{~A}$, and $* 7 \mathrm{~B}$ all represent slow acetylator genotypes), and the genetic model selection can be varied depending on the specific allelic variant. ${ }^{47}$ Therefore, the genetic models used in previous original and meta-analysis studies were adopted for these polymorphic genes in our current study. ${ }^{9}{ }^{18} 19$ Future studies are needed to comprehensively and adequately address the relationship between the ATDILI risk and various genetic polymorphisms by using different genetic risk models and including more polymorphic genotypes.

In conclusion, the risk of ATDILI during tuberculosis therapy was significantly increased in patients with tuberculosis carrying NAT2 slow acetylator, CYP2E1 RsaI/PstI c1/c1, or GSTM1 null genotypes. Screening for these genetic polymorphisms, particularly for the NAT2 slow acetylator genotype, may be of great clinical benefit to identify patients at high risk for ATDILI and minimise the risk of ATDILI. Future studies are pertinent to develop dose and/or treatment adjustment strategies, to evaluate the feasibility and cost-effectiveness of the genetic screening test, and to assess the effect of more genetic polymorphisms on the risk of ATDILI for optimal prevention and management of ATDILI.

\section{Author affiliations}

${ }^{1}$ Department of Pharmacy and Yonsei Institute of Pharmaceutical Science, Yonsei University, Incheon, Republic of Korea

${ }^{2}$ Department of Pharmacy, College of Pharmacy, Kyung Hee University, Seoul, Republic of Korea

${ }^{3}$ College of Pharmacy, Seoul National University, Seoul, Republic of Korea

${ }^{4}$ Department of Pharmacy, Kyung Hee University Hospital at Gangdong, Seoul, Republic of Korea

${ }^{5}$ College of Pharmacy and Research Institute of Pharmaceutical Sciences, Seoul National University, Seoul, Republic of Korea

Acknowledgements This study was supported by Research Resettlement Fund for the new faculty of Seoul National University. The authors thank Ms Kyeoul Jeong for her assistance in data management.

Contributors SY devised and designed the study. SY, JYP and SJH conducted the literature search, performed data extraction and analysis and interpreted the data. SY, EKC and JIL prepared and reviewed the manuscript. All authors reviewed, amended and approved the submitted manuscript.

Funding Research Resettlement Fund for the new faculty of Seoul National University provided funding to JIL. The funder had no role in data collection, data analysis, translation and drafting of the manuscript.

Competing interests None declared.

Patient consent for publication Not required.

Provenance and peer review Not commissioned; externally peer reviewed.

Data sharing statement № additional data are available.

Open access This is an open access article distributed in accordance with the Creative Commons Attribution Non Commercial (CC BY-NC 4.0) license, which permits others to distribute, remix, adapt, build upon this work non-commercially, and license their derivative works on different terms, provided the original work is properly cited, appropriate credit is given, 
any changes made indicated, and the use is non-commercial. See: http:// creativecommons.org/licenses/by-nc/4.0/.

\section{REFERENCES}

1. WHO. Global tuberculosis report Geneva. Switzerland: WHO, 2014

2. WHO. Treatment of tuberculosis guidelines. 4th edition. Geneva, Switzerland: WHO, 2010.

3. Blumberg HM, Burman WJ, Chaisson RE, et al. American Thoracic Society, Centers for Disease Control and Prevention and the Infectious Diseases Society. American Thoracic Society/Centers for Disease Control and Prevention/Infectious Diseases Society of America: treatment of tuberculosis. Am J Respir Crit Care Med 2003;167:603.

4. Zumla A, Raviglione M, Hafner R, et al. Tuberculosis. N Engl J Med Overseas Ed 2013;368:745-55.

5. Lange C, Abubakar I, Alffenaar JW, et al. TBNET. Management of patients with multidrug-resistant/extensively drug-resistant tuberculosis in Europe: a TBNET consensus statement. Eur Respir $J$ 2014;44:23-63.

6. Tostmann A, Boeree MJ, Aarnoutse RE, et al. Antituberculosis druginduced hepatotoxicity: concise up-to-date review. J Gastroenterol Hepatol 2008;23:192-202.

7. Saukkonen JJ, Cohn DL, Jasmer RM, et al. ATS (American Thoracic Society) Hepatotoxicity of Antituberculosis Therapy Subcommittee. An official ATS statement: hepatotoxicity of antituberculosis therapy. Am J Respir Crit Care Med 2006;174:935-52.

8. Yee D, Valiquette C, Pelletier M, et al. Incidence of serious side effects from first-line antituberculosis drugs among patients treated for active tuberculosis. Am J Respir Crit Care Med 2003;167:1472-7.

9. Cai Y, Yi J, Zhou C, et al. Pharmacogenetic study of drugmetabolising enzyme polymorphisms on the risk of anti-tuberculosis drug-induced liver injury: a meta-analysis. PLoS One 2012;7:e47769.

10. Kim SH, Kim SH, Lee JH, et al. Polymorphisms in drug transporter genes (ABCB1, SLCO1B1 and ABCC2) and hepatitis induced by antituberculosis drugs. Tuberculosis 2012;92:100-4.

11. Roy PD, Majumder M, Roy B. Pharmacogenomics of anti-TB drugsrelated hepatotoxicity. Pharmacogenomics 2008;9:311-21.

12. Sun F, Chen $Y$, Xiang $Y$, et al. Drug-metabolising enzyme polymorphisms and predisposition to anti-tuberculosis drug-induced liver injury: a meta-analysis. Int J Tuberc Lung Dis 2008;12:994-1002.

13. Chan SL, Chua APG, Aminkeng F, et al. Association and clinical utility of NAT2 in the prediction of isoniazid-induced liver injury in Singaporean patients. PLoS One 2017;12:e0186200.

14. Kerb R. Implications of genetic polymorphisms in drug transporters for pharmacotherapy. Cancer Lett 2006;234:4-33.

15. Cui Y, König J, Leier I, et al. Hepatic uptake of bilirubin and its conjugates by the human organic anion transporter SLC21A6. J Biol Chem 2001;276:9626-30.

16. Little J, Bradley L, Bray MS, et al. Reporting, appraising, and integrating data on genotype prevalence and gene-disease associations. Am J Epidemiol 2002;156:300-10.

17. Tang N, Deng R, Wang Y, et al. GSTM1 and GSTT1 null polymorphisms and susceptibility to anti-tuberculosis drug-induced liver injury: a meta-analysis. Int J Tuberc Lung Dis 2013;17:17-25.

18. Wang FJ, Wang Y, Niu T, et al. Update meta-analysis of the CYP2E1 Rsal/Pstl and Dral polymorphisms and risk of antituberculosis druginduced hepatotoxicity: evidence from 26 studies. J Clin Pharm Ther 2016;41:334-40.

19. Li C, Long J, Hu X, et al. GSTM1 and GSTT1 genetic polymorphisms and risk of anti-tuberculosis drug-induced hepatotoxicity: an updated meta-analysis. Eur J Clin Microbiol Infect Dis 2013;32:859-68.

20. Mantel N, Haenszel W. Statistical aspects of the analysis of data from retrospective studies of disease. J Natl Cancer Inst 1959;22:719-48.

21. DerSimonian R, Laird N. Meta-analysis in clinical trials. Control Clin Trials 1986;7:177-88.

22. Higgins JP, Thompson SG. Quantifying heterogeneity in a metaanalysis. Stat Med 2002;21:1539-58.

23. Feng FM, Guo M, Chen Y, et al. Genetic polymorphisms in metabolic enzymes and susceptibility to anti-tuberculosis drug-induced hepatic injury. Genet Mol Res 2014;13:9463-71.

24. Lv X, Tang S, Xia Y, et al. NAT2 genetic polymorphisms and antituberculosis drug-induced hepatotoxicity in Chinese community population. Ann Hepatol 2012;11:700-7.

25. Wattanapokayakit S, Mushiroda T, Yanai H, et al. NAT2 slow acetylator associated with anti-tuberculosis drug-induced liver injury in Thai patients. Int J Tuberc Lung Dis 2016;20:1364-9.

26. Singla N, Gupta D, Birbian N, et al. Association of NAT2, GST and CYP2E1 polymorphisms and anti-tuberculosis drug-induced hepatotoxicity. Tuberculosis 2014;94:293-8.
27. Gupta VH, Amarapurkar DN, Singh M, et al. Association of $\mathrm{N}$-acetyltransferase 2 and cytochrome P450 2E1 gene polymorphisms with antituberculosis drug-induced hepatotoxicity in Western India. J Gastroenterol Hepatol 2013;28:1368-74.

28. Li LM, Chen L, Deng GH, et al. SLCO1B1 *15 haplotype is associated with rifampin-induced liver injury. Mol Med Rep 2012;6:75-82.

29. Wang P-Y, Xie S-Y, Hao Q, et al. NAT2 polymorphisms and susceptibility to anti-tuberculosis drug-induced liver injury: a metaanalysis [Review article]. The International Journal of Tuberculosis and Lung Disease 2012;16:589-95.

30. Deng R, Yang T, Wang Y, et al. CYP2E1 Rsal/Pstl polymorphism and risk of anti-tuberculosis drug-induced liver injury: a meta-analysis. Int J Tuberc Lung Dis 2012;16:1574-81.

31. Mitchell JR, Zimmerman HJ, Ishak KG, et al. Isoniazid liver injury: clinical spectrum, pathology, and probable pathogenesis. Ann Intern Med 1976;84:181-92.

32. Ryan DE, Ramanathan L, lida S, et al. Characterization of a major form of rat hepatic microsomal cytochrome P-450 induced by isoniazid. J Biol Chem 1985;260:6385-93.

33. Ortega VE, Meyers DA. Pharmacogenetics: implications of race and ethnicity on defining genetic profiles for personalized medicine. $J$ Allergy Clin Immunol 2014;133:16-26.

34. Bliven-Sizemore EE, Sterling TR, Shang N, et al. TB Trials Consortium. Three months of weekly rifapentine plus isoniazid is less hepatotoxic than nine months of daily isoniazid for LTBI. Int $J$ Tuberc Lung Dis 2015;19:1039-44. i-v.

35. Zhou Y, Ingelman-Sundberg M, Lauschke VM. Worldwide Distribution of Cytochrome P450 Alleles: A Meta-analysis of Population-scale Sequencing Projects. Clin Pharmacol Ther 2017;102:688-700.

36. Lin $\mathrm{HJ}$, Han $\mathrm{CY}$, Lin BK, et al. Ethnic distribution of slow acetylator mutations in the polymorphic $\mathrm{N}$-acetyltransferase (NAT2) gene. Pharmacogenetics 1994;4:125-34.

37. Seng KY, Hee KH, Soon GH, et al. Population pharmacokinetic analysis of isoniazid, acetylisoniazid, and isonicotinic acid in healthy volunteers. Antimicrob Agents Chemother 2015;59:6791-9.

38. Wang P, Pradhan K, Zhong XB, et al. Isoniazid metabolism and hepatotoxicity. Acta Pharm Sin B 2016;6:384-92.

39. Metushi IG, Nakagawa T, Uetrecht J. Direct oxidation and covalent binding of isoniazid to rodent liver and human hepatic microsomes: humans are more like mice than rats. Chem Res Toxicol 2012;25:2567-76.

40. Ramachandran G, Swaminathan S. Role of pharmacogenomics in the treatment of tuberculosis: a review. Pharmgenomics Pers Med 2012;5:89-98.

41. Kasthurinaidu SP, Ramasamy T, Ayyavoo J, et al. GST M1-T1 null allele frequency patterns in geographically assorted human populations: a phylogenetic approach. PLoS One 2015;10:e0118660.

42. Chen R, Wang J, Tang S, et al. Association of polymorphisms in drug transporter genes (SLCO1B1 and SLC10A1) and anti-tuberculosis drug-induced hepatotoxicity in a Chinese cohort. Tuberculosis 2015:95:68-74.

43. Weiner M, Peloquin C, Burman W, et al. Effects of tuberculosis, race, and human gene SLCO1B1 polymorphisms on rifampin concentrations. Antimicrob Agents Chemother 2010;54:4192-200.

44. Chigutsa E, Visser ME, Swart EC, et al. The SLCO1B1 rs4149032 polymorphism is highly prevalent in South Africans and is associated with reduced rifampin concentrations: dosing implications. Antimicrob Agents Chemother 2011;55:4122-7.

45. Yimer G, Ueda N, Habtewold A, et al. Pharmacogenetic \& pharmacokinetic biomarker for efavirenz based ARV and rifampicin based anti-TB drug induced liver injury in TB-HIV infected patients. PLoS One 2011;6:e27810.

46. Chen R, Wang J, Zhang Y, et al. Key factors of susceptibility to anti-tuberculosis drug-induced hepatotoxicity. Arch Toxicol 2015;89:883-97.

47. Khan S, Mandal RK, Elasbali AM, et al. Pharmacogenetic association between NAT2 gene polymorphisms and isoniazid induced hepatotoxicity: trial sequence meta-analysis as evidence. Biosci Rep 2019;39:BSR20180845

48. Kim SH, Kim SH, Bahn JW, et al. Genetic polymorphisms of drug-metabolizing enzymes and anti-TB drug-induced hepatitis. Pharmacogenomics 2009;10:1767-79.

49. Singh M, Gupta VH, Amarapurkar DN, et al. Association of genetic variants with anti-tuberculosis drug induced hepatotoxicity: a high resolution melting analysis. Infect Genet Evol 2014;23:42-8.

50. Tang S, Lv X, Zhang Y, et al. Cytochrome P450 2E1 gene polymorphisms/haplotypes and anti-tuberculosis drug-induced hepatitis in a Chinese cohort. PLoS One 2013;8:e57526.

51. Ben Mahmoud L, Ghozzi H, Kamoun A, et al. Polymorphism of the $\mathrm{N}$-acetyltransferase 2 gene as a susceptibility risk factor for 
antituberculosis drug-induced hepatotoxicity in Tunisian patients with tuberculosis. Pathol Biol 2012;60:324-30.

52. Bozok Cetintaș V, Erer OF, Kosova B, et al. Determining the relation between $\mathrm{N}$-acetyltransferase-2 acetylator phenotype and antituberculosis drug induced hepatitis by molecular biologic tests. Tuberk Toraks 2008;56:81-6.

53. Higuchi N, Tahara N, Yanagihara K, et al. NAT2 6A, a haplotype of the $\mathrm{N}$-acetyltransferase 2 gene, is an important biomarker for risk of anti-tuberculosis drug-induced hepatotoxicity in Japanese patients with tuberculosis. World J Gastroenterol 2007;13:6003-8.

54. Ho HT, Wang TH, Hsiong CH, et al. The NAT2 tag SNP rs1495741 correlates with the susceptibility of antituberculosis drug-induced hepatotoxicity. Pharmacogenet Genomics 2013;23:200-7.

55. Huang YS, Chern HD, Su WJ, et al. Polymorphism of the $\mathrm{N}$-acetyltransferase 2 gene as a susceptibility risk factor for antituberculosis drug-induced hepatitis. Hepatology 2002;35:883-9.

56. Khalili $\mathrm{H}$, Fouladdel S, Sistanizad M, et al. Association of $\mathrm{N}$-acetyltransferase-2 genotypes and anti-tuberculosis induced liver injury; first case-controlled study from Iran. Curr Drug Saf $2011 ; 6: 17-22$.

57. Leiro-Fernandez V, Valverde D, Vázquez-Gallardo R, et al. Nacetyltransferase 2 polymorphisms and risk of anti-tuberculosis drug-induced hepatotoxicity in Caucasians. Int $J$ Tuberc Lung Dis 2011;15:1403-8.

58. Ng CS, Hasnat A, Al Maruf A, et al. N-acetyltransferase 2 (NAT2) genotype as a risk factor for development of drug-induced liver injury relating to antituberculosis drug treatment in a mixed-ethnicity patient group. Eur J Clin Pharmacol 2014;70:1079-86.

59. Ohno M, Yamaguchi I, Yamamoto I, et al. Slow N-acetyltransferase 2 genotype affects the incidence of isoniazid and rifampicin-induced hepatotoxicity. Int J Tuberc Lung Dis 2000;4:256-61.

60. Possuelo LG, Castelan JA, de Brito TC, et al. Association of slow $\mathrm{N}$-acetyltransferase 2 profile and anti-TB drug-induced hepatotoxicity in patients from Southern Brazil. Eur J Clin Pharmacol 2008;64:673-81.

61. Rana SV, Ola RP, Sharma SK, et al. Comparison between acetylator phenotype and genotype polymorphism of n-acetyltransferase-2 in tuberculosis patients. Hepatol Int 2012;6:397-402.

62. Shimizu Y, Dobashi K, Mita Y, et al. DNA microarray genotyping of $\mathrm{N}$-acetyltransferase 2 polymorphism using carbodiimide as the linker for assessment of isoniazid hepatotoxicity. Tuberculosis 2006;86:374-81.

63. Yuliwulandari R, Susilowati RW, Wicaksono BD, et al. NAT2 variants are associated with drug-induced liver injury caused by antituberculosis drugs in Indonesian patients with tuberculosis. J Hum Genet 2016;61:533-7.

64. Chatterjee S, Lyle N, Mandal A, et al. GSTT1 and GSTM1 gene deletions are not associated with hepatotoxicity caused by antitubercular drugs. J Clin Pharm Ther 2010;35:465-70.

65. Gupta VH, Singh M, Amarapurkar DN, et al. Association of GST null genotypes with anti-tuberculosis drug induced hepatotoxicity in Western Indian population. Ann Hepatol 2013;12:959-65.

66. Huang YS, Su WJ, Huang YH, et al. Genetic polymorphisms of manganese superoxide dismutase, $\mathrm{NAD}(\mathrm{P}) \mathrm{H}$ :quinone oxidoreductase, glutathione S-transferase $\mathrm{M} 1$ and $\mathrm{T} 1$, and the susceptibility to drug-induced liver injury. J Hepatol 2007;47:128-34.

67. Kim SH, Kim SH, Yoon HJ, et al. GSTT1 and GSTM1 null mutations and adverse reactions induced by antituberculosis drugs in Koreans. Tuberculosis 2010;90:39-43.

68. Leiro V, Fernández-Villar A, Valverde D, et al. Influence of glutathione S-transferase M1 and T1 homozygous null mutations on the risk of antituberculosis drug-induced hepatotoxicity in a Caucasian population. Liver Int 2008;28:835-9.

69. Liu F, Jiao A-xia, Wu X-rong, et al. Impact of Glutathione S-Transferase M1 and T1 on Anti-Tuberculosis Drug-Induced Hepatotoxicity in Chinese Pediatric Patients. PLoS One 2014;9:9:e115410.

70. Monteiro TP, El-Jaick KB, Jeovanio-Silva AL, et al. The roles of GSTM1 and GSTT1 null genotypes and other predictors in anti-tuberculosis drug-induced liver injury. J Clin Pharm Ther 2012;37:712-8.

71. Rana SV, Kamboj JK, Sharma SK, et al. Antioxidant status and GST gene polymorphisms in antitubercular treatment-induced hepatotoxicity patients. Hepatol Int 2013;7:876-82.

72. Roy B, Chowdhury A, Kundu S, et al. Increased risk of antituberculosis drug-induced hepatotoxicity in individuals with glutathione S-transferase M1 'null' mutation. J Gastroenterol Hepatol 2001;16:1033-7.

73. An HR, Wu XQ, Wang ZY, et al. NAT2 and CYP2E1 polymorphisms associated with antituberculosis drug-induced hepatotoxicity in Chinese patients. Clin Exp Pharmacol Physiol 2012;39:535-43.

74. Bose PD, Sarma MP, Medhi S, et al. Role of polymorphic N-acetyl transferase2 and cytochrome P4502E1 gene in antituberculosis treatment-induced hepatitis. J Gastroenterol Hepatol 2011;26:312-8.

75. Chamorro JG, Castagnino JP, Musella RM, et al. Sex, ethnicity, and slow acetylator profile are the major causes of hepatotoxicity induced by antituberculosis drugs. J Gastroenterol Hepatol 2013;28:323-8

76. Cho HJ, Koh WJ, Ryu YJ, et al. Genetic polymorphisms of NAT2 and CYP2E1 associated with antituberculosis drug-induced hepatotoxicity in Korean patients with pulmonary tuberculosis. Tuberculosis 2007;87:551-6.

77. Huang YS, Chern HD, Su WJ, et al. Cytochrome P450 2E1 genotype and the susceptibility to antituberculosis drug-induced hepatitis. Hepatology 2003;37:924-30.

78. Lee SW, Chung LS, Huang HH, et al. NAT2 and CYP2E1 polymorphisms and susceptibility to first-line anti-tuberculosis druginduced hepatitis. Int J Tuberc Lung Dis 2010;14:622-6.

79. Mishra S, Daschakraborty S, Shukla P, et al. N-acetyltransferase and cytochrome $\mathrm{P} 4502 \mathrm{E} 1$ gene polymorphisms and susceptibility to antituberculosis drug hepatotoxicity in an Indian population. Nat Med J India 2013;26:260-5.

80. Santos NP, Callegari-Jacques SM, Ribeiro Dos Santos AK, et al. N-acetyl transferase 2 and cytochrome P450 2E1 genes and isoniazid-induced hepatotoxicity in Brazilian patients. Int $J$ Tuberc Lung Dis 2013;17:499-504.

81. Vuilleumier N, Rossier MF, Chiappe A, et al. CYP2E1 genotype and isoniazid-induced hepatotoxicity in patients treated for latent tuberculosis. Eur J Clin Pharmacol 2006;62:423-9.

82. Yamada S, Tang M, Richardson K, et al. Genetic variations of NAT2 and CYP2E1 and isoniazid hepatotoxicity in a diverse population. Pharmacogenomics 2009;10:1433-45.

83. Zaverucha-do-Valle C, Monteiro SP, El-Jaick KB, et al. The role of cigarette smoking and liver enzymes polymorphisms in antituberculosis drug-induced hepatotoxicity in Brazilian patients. Tuberculosis 2014:94:299-305.

84. Sharma SK, Jha BK, Sharma A, et al. Genetic polymorphisms of CYP2E1 and GSTM1 loci and susceptibility to antituberculosis drug-induced hepatotoxicity. Int J Tuberc Lung Dis 2014;18:588-93.

85. Wang T, Yu HT, Wang W, et al. Genetic polymorphisms of cytochrome P450 and glutathione S-transferase associated with antituberculosis drug-induced hepatotoxicity in Chinese tuberculosis patients. J Int Med Res 2010;38:977-86.

86. Tang SW, Lv XZ, Zhang Y, et al. CYP2E1, GSTM1 and GSTT1 genetic polymorphisms and susceptibility to antituberculosis drug-induced hepatotoxicity: a nested case-control study. J Clin Pharm Ther 2012;37:588-93.

87. Brito TC, POSSUELO LIAG, Valim ARM, et al. Polymorphisms in CYP2E1, GSTM1 and GSTT1 and anti-tuberculosis druginduced hepatotoxicity. Anais da Academia Brasileira de Ciências 2014;86:855-65.

88. Forestiero FJ, Cecon L, Hirata MH, et al. Relationship of NAT2, CYP2E1 and GSTM1/GSTT1 polymorphisms with mild elevation of liver enzymes in Brazilian individuals under anti-tuberculosis drug therapy. Clin Chim Acta 2013;415:215-9.

89. Rana SV, Sharma SK, Ola RP, et al. N-acetyltransferase 2, cytochrome P4502E1 and glutathione S-transferase genotypes in antitubercular treatment-induced hepatotoxicity in North Indians. $J$ Clin Pharm Ther 2014;39:91-6.

90. Sotsuka T, Sasaki Y, Hirai S, et al. Association of isoniazidmetabolizing enzyme genotypes and isoniazid-induced hepatotoxicity in tuberculosis patients. In Vivo 2011;25:803-12.

91. Teixeira RL, Morato RG, Cabello PH, et al. Genetic polymorphisms of NAT2, CYP2E1 and GST enzymes and the occurrence of antituberculosis drug-induced hepatitis in Brazilian TB patients. Mem Inst Oswaldo Cruz 2011;106:716-24.

92. Xiang $\mathrm{Y}, \mathrm{Ma} \mathrm{L}, \mathrm{Wu} \mathrm{W}$, et al. The Incidence of Liver Injury in Uyghur Patients Treated for TB in Xinjiang Uyghur Autonomous Region, China, and Its Association with Hepatic Enzyme Polymorphisms NAT2, CYP2E1, GSTM1 and GSTT1. PLoS One 2014;9:e85905:9. 